\title{
The Maturity Process of Pi in Life of Pi
}

\section{Gracia Purnomo}

English Department, Faculty of Letters, Petra Christian University, Siwalankerto 121-131, Surabaya 60236, INDONESIA.

Email:m11415019@john.petra.ac.id

\begin{abstract}
This thesis discusses the process of maturity of Pi in Life of Pi. I am curious to find out how Pi is mature from his childhood, teenager, and adulthood. Therefore, I use Erik Erikson's theory of psychosocial development to find out the influence of the society that Pi lives in. In each stage of Pi's development, I study his character traits and I see the outcome. In addition, I am using psychological development to find out what is inside Pi's mind and what is his way of thinking. Throughout the process, Pi faces some obstacles or psychosocial crisis from his surroundings especially from his father and friends in his childhood and early teenager years. However, because of the obstacles from his surroundings, Pi becomes mature in taking his actions and decisions. In addition, Pi faces a big situation that is surviving in the sea with Richard Parker. I can see from this experience, Pi finds his identities that are self-acceptance, compassion, patience, honesty, gratitude, self-control, accountability, open-mindedness, and humility. Despite the hardship from his childhood and teenage years, Pi manages to be emotionally mature. As a result, $\mathrm{Pi}$ is indeed mature in his life and it can be seen in his adulthood. Pi has an intimate relationship with his wife and children.
\end{abstract}

Keywords: Maturity Process, Identity, Role Confusion, Adulthood, Life of Pi

\section{INTRODUCTION}

Psychological fiction genre is not widely used in movies. Rather than psychological fiction, psychological thriller and psychological drama are the most popular ones. Even though this genre is not popular in movies, I believe that this is a good genre to know more about the characters' actions and why they do that. Through this genre, the characters' personalities, emotions, and struggles can be seen. Psychology makes people understand more about how the body and mind work together. According to Philippe (2017), the knowledge can help the character in making decisions, managing time, achieving goals, and living effectively. That is why I am interested to analyze a movie that belongs to this genre.

The movie that belongs to psychological fiction is Life of Pi which is adapted from Yann Martel's novel. This movie is directed by a famous producer, director, and filmmaker, Ang Lee. This movie is quite controversial because it questions God's existence. However, while other people tend to focus on the existence of God, I am interested to know more about Pi. The movie shows when $\mathrm{Pi}$ is a child until he is an adult. In the process, he goes through a lot of experience in his journey. I believe Pi has gone through some changes in him not only physically but also emotionally. That is why I am interested to know Pi's process of maturity in his life from a child to an adult.

Life of Pi focuses on a sixteen-year-old boy named Pi and a Bengal tiger named Richard Parker who survive in a boat together. Pi's family is drowned in the sea because their ship sinks. Pi and the Bengal Tiger are the only ones who survive. When Pi's family die in the shipwreck, he is in despair. Pi, along with the tiger, survives in the sea. Since he was a child, he has lived very well and organized in the safety and care from his family especially his mom, but now he has to survive alone. The sudden separation from his family forces him to learn how to survive and 
deal with challenges in front of him. He has to face the problem himself in the sea as a teenager and that must be hard for him to adapt to the situation.

Because I am interested how Pi changes in his life, my focus on this analysis is about Pi's maturity. In the movie, it shows Pi when he was a child, teenager, and adult. His childhood was spent happily with his family in India and Pi was quite a rebel and carefree child. He then has to face the bitter reality that his family died, forcing him to live alone with the tiger. In the end, it shows that he has a happy life with his wife and children far from his hometown. Through the process, I believe that he changes not only physically but emotionally. The process from $\mathrm{Pi}$ as a child to an adult is the process of maturity. According to Nangia (2016), to be mature, one must be willing to learn from experiences, adapt to the changes and large-heartedness to respect the differences and viewpoints of others. I am curious how Pi becomes mature person when he is a child, a teenager, and an adult. As I know, a person is considered mature when he or she is an adult, but actually a person can mature in his or her childhood.

To study Pi's process of maturity in Life of Pi, I use Erik Erikson's theory of psychosocial development. Erik Erikson is a German-American developmental psychologist who developed a popular theory of development. He is one of the most influential psychoanalysts on the $20^{\text {th }}$ century. According to Anardacci (2016), Erikson talks about maturity in his stages of psychosocial development. His theory was influenced by Sigmund Freud's work. Erikson's theory focuses on psychosocial development. Just like Sigmund Freud, he believes that personality is developed in a series of stages.

These are the stages of Erik Erikson's theory:

\begin{tabular}{|l|l|l|}
\hline Stage & Psychosocial Development & Age \\
\hline 1 & Trust vs. Mistrust & $0-1.5$ \\
\hline 2 & Autonomy vs. Shame and Doubt & $1.5-3$ \\
\hline 3 & Initiative vs. Guilt & $3-5$ \\
\hline 4 & Industry vs. Inferiority & $5-12$ \\
\hline 5 & Identity vs. Role Confusion & $12-18$ \\
\hline 6 & Intimacy vs. Isolation & $18-40$ \\
\hline 7 & Generativity vs. Stagnation & $40-65$ \\
\hline 8 & Integrity vs. Despair & $65+$ \\
\hline
\end{tabular}

In each stage of psychosocial development, a person experiences psychosocial crisis. According to Cherry (2019), Psychosocial crisis is a conflict that serves to be a turning point in a development. The psychosocial crisis is needed so that a person can be mature in each stage. Psychosocial crisis is also applied in Pi's stages of psychosocial development since he is a child through his father and friends. I show the crisis in each stage and how the problems are clashing inside Pi. Psychosocial development and psychosocial crisis are needed because they can help Pi to be mature in his or her own way.

Besides psychosocial development, I also show Pi's psychological development to show that he is mature in his life. Psychosocial development is when the society contributes to the process of maturity, while psychological development is about studying the behavior and mind. 
Psychological development is also as important as psychosocial development for Pi. It is to show how Pi's surrounding can affect Pi's actions and decisions. It is because all the influence that the society give are all develop in Pi's mind, so all of his actions and decisions come from his mind.

\begin{abstract}
ANALYSIS
This chapter discusses the process of maturity of Pi when he is a child, a teenager, and an adult. I use Erik Erikson's theory of psychosocial development stages starting from the third stage to the sixth stage to prove that Pi matures in each stage. In each stage, I show the psychosocial crisis that happens in Pi and his surroundings. Besides psychosocial development, I show his psychological development as an effect that he gets from his social life. In addition, Pi shows his character traits to overcome the crisis in each stages of his development to be mature.
\end{abstract}

\title{
Pi as a Child
}

In this stage, I show that Pi's mother and father can influence Pi as a child. The first social interaction that $\mathrm{Pi}$ has is with his family that is why his parents influence him psychosocially. $\mathrm{Pi}$ as a child grows an attachment towards his mother rather than his father. The reason why Pi does not grow an attachment towards his father is because of the guilt and inferiority that affect $\mathrm{Pi}$ as a child. The result of this stage is Pi becomes an initiative and industrious person.

\section{Pi as an Initiative Person}

In his development to be mature, Pi develops courage, determination, and optimism. These character traits help Pi to become mature in his childhood. These character traits make Pi gains purpose in his life. Additionally, Pi's purpose or goal in his life can be achieved by having these character traits. In this stage, Pi needs to experience some obstacles or crisis that are caused by his surroundings. Pi becomes mature when he has the purpose in his life and he works to achieve it. I can see that Pi matures in his childhood because Pi gains purpose in his life.

As Pi develop to be mature, he also faces guilt. Guilt is needed in the process of maturity so that Pi knows what is right or wrong. It helps him to think more carefully. I believe he is able to decide what the best is and that is an act of a mature person if he thinks carefully. Furthermore, guilt comes from social life or the external factor. The feeling of guilt in Pi comes from his father and friends.

Pi's courage, determination, and optimism are much stronger than his feeling of guilt. From looking at how Pi can overcome the guilt that his father and friends give to him, I can say that he has undergone the process of maturity. As Erik Erikson said, if guilt is stronger than initiative, a person has self-doubt. In this case, Pi does not have self-doubt. His behavior does not show that he has self-doubt or not confident in whatever he does. He takes the guilt but it does not let the guilt dominate him. He takes the guilt to be a consideration to what he is going to decide. I believe Pi knows his purpose and has undergone the process of maturity because he develops courage, determination, and optimism in his childhood.

\section{Pi as an Industrious Person}

Pi as a child also develops another character traits besides courage, determination, and optimism for his process of maturity. These character traits are diligent and hard-working. Diligent means that a person has a persistent work or effort. Meanwhile, hard-working means a person puts a lot of effort to achieve what he or she wants. Because Pi is a diligent and hard-working person, he 
has competence. According to the Merriam-Webster dictionary, competence means the quality or state of having sufficient knowledge, judgment, skill, or strength. When Pi has competence in his life, it shows that he has gone through the process of maturity.

In addition, Pi needs to experience a crisis that is inferiority because of the superiority from Pi's father and friends that affect $\mathrm{Pi}$ as a child. Inferiority is the condition of being lower in status and quality than other people. Inferiority is needed for $\mathrm{Pi}$, so that he knows what he does is right or wrong. It helps him to know that there is something wrong in his action, and he should fix it. Therefore, $\mathrm{Pi}$ is able to decide what he going to do next carefully, and that is an act of a mature person. If Pi has inferiority, there must be someone who has superiority. A person who has superiority thinks that he or she has control for other people who is lower than him or her.

Pi's diligence and hard-working nature are stronger than his feeling of inferiority that comes from his environment. From looking at how Pi can overcome the inferiority that his father and friends influence to him, I can say that he has undergoes the process of maturity. Like Erik Erikson said, if inferiority is stronger than industrious, a person does not have pride. In this case, Pi does not have pride. His behavior does not show that he has pride or not confident in whatever he does. He does not let the inferiority dominates him. He is influenced by his father and friends' superiority to be able to understand what is going wrong and from that, he knows his next step to fix it. I believe Pi becomes a competent person because looking at his sufficiency of knowledge, skill, and strength. Therefore, Pi has undergone the process of maturity because he develops diligence and hard-working character trait in his childhood.

\section{Pi as a Teenager}

I show the role confusion that Pi experiences to find his identity and when Pi finally has his identity. I use the psychosocial development which studies how parents and friends affect Pi and how Pi reacts to them. I also analyze Pi's psychological development because in this stage he is in the sea for 227 days and there is not much interaction with parents and friends. From I can get from the relationship between Pi and Richard Parker, I can say that Richard Parker is like a metaphor of a friend for Pi throughout his journey. It is true that in Pi teenager life, his parents and friends do not have enough role to affect Pi, but I see that Richard Parker is the substitute for Pi's parents and friends. So, I study his psychology by looking at his behavior and mind through his monologue to show the role confusion that Pi is going through and how he finds his identity.

\section{The Role Confusion in Pi's Life}

$\mathrm{Pi}$ as a teenager shows signs that he experiences role confusion in his process of maturity. The three signs that he is in a role confusion are limited, boredom, and rebellious. There is possible role confusion when he is in the sea with Richard Parker. I can also see that the environment also takes part in making Pi experiences role confusion in his process of maturity.

$\mathrm{Pi}$ is affected by his father's guilt and superiority. It is shown that guilt and superiority can have a good side and a bad side. The good side of guilt and superiority are to make Pi knows what is right and wrong in his actions, while the bad side of guilt and superiority are to make Pi feels limited and he is unhappy because of it. Even though he can overcome those things when he is still a child, guilt and inferiority are still inside of him to make Pi realize that he cannot do anything he wants freely. I can say that he is mature because he thinks that whether his actions make people around him happy or not. Environment or people that surround him actually helps Pi finds his identity, but ever since he was a child, he does not have any supportive family or friends and that makes Pi harder to find his identity. This shows that Pi is limited because of his environment as a sign that he experiences role confusion in his process of maturity. 
There is also a possible role confusion that is occurring at the sea when he is with Richard Parker. Because in the sea Pi cannot interact with other people, the only one who he can interact is with Richard Parker, the tiger. The role confusion that Pi feels is whether he needs to be a friend or an enemy for Richard Parker. This is because when Pi is a child, his father tells him that the tiger is not his friend. Therefore, Pi thinks that Richard Parker is not his friend. On the other hand, he cannot kill Richard Parker. In this case, Pi cannot position himself whether he should be an enemy or a friend for Richard Parker.

\section{The Findings of Pi's Identity}

The signs that he finds his identity is he has self-acceptance, compassion, patience, honesty, gratitude, self-control, accountability, open-mindedness, and humility. I can see that the effect from the surrounding since he was a child until teenager takes a part in his search for his identity even though he is on the sea for 227 days. According to Cambridge Dictionary, identity means who a person is, or the qualities of a person that makes them different from others. When Pi finds his identity, it shows that he undergoes the process of maturity.

Pi shows that he is matured when he is a teenager because he is able to rely on himself and take care of Richard Parker at the same time. He can solve his problem by thinking smart and acting fast. Another prove that he is mature is he can take his own decisions independently. Pi lives on his own at the sea so he should make his own decisions for him and Richard Parker. Those are the things that I believe Pi has undergone the process of maturity by finding his identity when he is a teenager.

\section{Pi as an Adult}

$\mathrm{Pi}$ is mature after all the experiences throughout his childhood and teenage life. Furthermore, adulthood is mostly about a relationship with the people who interact with $\mathrm{Pi}$. I show that Pi is indeed mature because he manages to have an intimate relationship with his wife, children, and the writer. From Pi, I can see that he succeeded in maintaining a good relationship. Even though he has a hard relationship in his past with his father and friends, he is able to create a good relationship. I can also see that Pi strengthen his past character traits and that makes him mature.

In Pi's process of maturity, he has become an intimate person in his adulthood. I prove that after his development to become mature in previous stages, Pi explores personal relationship in this stage. Erikson believes that it is important that people should develop a close relationship with other people. To know whether the relationship is successful or not, I can see from Pi's condition.

I can see that Pi does not push his belief to other people, unlike his past experience with his father who pushes his believe to Pi. Another thing that I can see from Pi is how he talks with such kindness, his actions that show compassion, and how he positions himself to be equal with the one whom he talks. I believe that Pi as an adult has become successful materially. It is shown by how Pi has a nice house and he also has food to eat. From the examples above, I can say that Pi has become mature as an adult after looking back at his past experiences.

As a result, $\mathrm{Pi}$ is mature in his adulthood and develops a good relationship with other people. $\mathrm{Pi}$ shows that he is an intimate person from how he treats his wife and children with kindness and compassion. Erik Erikson said that if a person cannot figure out his or her identity, still in selfdoubt, still have a feeling of inferiority, he or she might fail in a relationship and isolated. That statement does not prove through Pi because in the previous stages, he is successful and gains 
character traits that show how he undergoes his process of maturity. Also, for people who still do not know what they are going to do, they do not have confidence and do not have a close relationship with other because they still need to figure those things out for themselves and they do not have time to care for other people or even the next generations. Pi does not belong to that statement because as I can see, he has much confidence and shows his care towards the next generations that are his kids. I can say that $\mathrm{Pi}$ is mature in his adulthood by looking at the result of his intimate relationship that he builds with his wife, children, and the writer.

\section{CONCLUSION}

In this research, I can say that society can influence Pi to be mature. First, it is shown by how Pi does not have an attachment towards his father because his father does not show how affectionate he is. Second, it is shown by how Pi is mocked and rejected by his friends. I think that society is a huge influence for a person. However, there are good and bad sides of the influence that I can see from Pi. The good side is that it makes Pi reconsider his actions and his way of thinking. Meanwhile, the bad side can make Pi become limited and bored. Despite the bad effect of the society to Pi, Pi can manage to overcome it. This shows that Pi is an emotionally mature person because he does not let society dominate him, but he uses that to think about his actions. Overall, I think that the influence of the society is needed for Pi because it affects his psychology and it shows in actions as an emotionally mature person.

In addition, I think psychosocial development in a person affects more than the psychological development. The process of maturity is mostly because of the psychosocial development in each stage of human life. In addition, psychological development is also a factor for a person to be mature. Even though psychological development is also a contributing factor for a person to be mature, psychosocial development dominates more because in life, a person always interacts with other people. Like it or not, the surrounding has a part in shaping a person's personality. I found that $\mathrm{Pi}$ is a strong person in this psychosocial development because he does not let the society dominates him. I can see that Pi's surrounding is very harsh towards Pi ever since he is a child, but in the end, Pi can be a strong and successful human being.

Besides, I found that the relationship between Pi and Richard Parker is interesting. I can see that Richard Parker is like a substitute or more likely a metaphor for Pi's family and friends when they are on the sea for 227 days. Even though at first, Pi is confused whether to position himself as a friend or an enemy, in the end, he manages to become a friend for Richard Parker. Because of Richard Parker, Pi finds his identity. As I can see in chapter 2.2.2 when Pi finds his identity, Pi gets all his identity mostly because of Richard Parker existences. For example when Pi shows that he is a compassionate person, Pi feels sympathetic towards Richard Parker and does not let him die. That proves that Pi shows an act of a compassionate person. Furthermore, Richard Parker also teaches Pi to survive in the sea. This is because Pi's fear of Richard Parker that makes him survive at the sea. After that, it turns out that behind his fear, he actually loves and cares about Richard Parker. I think Pi realizes that the teaching from his father when he is a child turns out to be wrong. Animals have souls. They can think and feel too. That is why in the end, Pi becomes a friend for Richard Parker. To sum up, Pi becomes a mature teenager because he finds his identity through Richard Parker's help.

Another thing is that a person can be mature when he or she is a child, a teenager or an adult. To be mature, a person does not have to wait until he or she is an adult. It can be shown through Pi ever since he is a child. Pi is different from other kids at school because he is not weird, but he is mature. He has his own way of thinking and it is not weird, he is mature. People often think that when a child is different, he or she must be weird, but it can be because he or she is mature at his or her age. There are some adult who are not yet mature and that is shown how he or she 
becomes isolated from the society. In short, in every stage of human life, a person can be mature.

In conclusion, this film shows the maturity of the main character in his stages of life. $\mathrm{Pi}$, the main character, undergoes the process of maturity from his childhood, teenager and adulthood. To analyze his maturity, I have used the psychosocial development from Erik Erikson and it turns out that Pi can overcome the obstacle or the psychosocial crisis in each stage. Moreover, the obstacle or crisis is absolutely needed to make Pi considers his decisions and actions. Besides, psychosocial development, I also use psychological development of Pi. Psychosocial and psychology factors have a great role and importance to make Pi matures in his childhood until adulthood. Because of it, Pi makes a decision based on the influence of society and his own understanding. In addition, I think these findings make me understand that a person needs other people to become mature. Furthermore, a person can be mature in any stage of life. In the end, I can say that Pi is mature in his life.

This research can encourage further research because this research is not enough. This research can encourage other research especially to analyze more about the role of Richard Parker, the tiger, as Pi's companion at the sea. Even though in this research I have talked about Richard Parker, I believe his role has deeper meaning. Richard Parker is a unique character in Life of Pi because he is personified in this movie. That is why it would be interesting to know more about Richard Parker's personality, intention, action, and many more. Therefore, I think for further research, it will be good to find out more about Richard Parker's role.

\section{REFERENCES}

Anardacci. (2016). Maturity through erikson's stages of psychosocial development. Retrieved November 2, 2016, from https://modelsofmaturityblog.wordpress.com/2016/11/02/maturity-through-eriksonsstages-of-psychosocial-development/

Cherry, K. (2019). Erik erikson's stages of psychosocial development. Retrieved June 25, 2019, from https://www.verywellmind.com/erik-eriksons-stages-of-psychosocialdevelopment-2795740

Nangia, V. D. (2016). What does it mean to be mature? Retrieved May 29, 2016 from https://timesofindia.indiatimes.com/blogs/O-zone/what- ${ }^{\text {does }}$-it-mean-to-be-mature/

Philippe, R. (2017). The importance of psychology. Retrieved September 9, 2017, from https://owlcation.com/social-sciences/Psychology-and-its-Importance 